\title{
Poly(glutamic acid) poly(ethylene glycol) hydrogels prepared by photoinduced polymerization: Synthesis, characterization, and preliminary release studies of protein drugs
}

\author{
Zhiqiang Yang, ${ }^{*}$ Yuehua Zhang, ${ }^{\dagger}$ Peter Markland, ${ }^{\ddagger}$ Victor C. Yang \\ College of Pharmacy, The University of Michigan, Ann Arbor, Michigan 48109-1065
}

Received 3 May 2001; revised 11 December 2001; accepted 10 January 2002

\begin{abstract}
A class of new biodegradable hydrogels based on poly(ethylene glycol) methacrylate-graft-poly(glutamic acid) and poly(ethylene glycol) dimethacrylate was synthesized by photoinduced polymerization. Because all the polymeric constituents were highly hydrophilic, crosslinking could be performed in aqueous solutions. This type of crosslinked hydrogel was prepared by modifying a select number of acidic side-groups on poly(glutamic acid) with poly(ethylene glycol) methacrylate. These modified chains were then crosslinked in the presence of poly(ethylene glycol) dimethacrylate under a photoinduced polymerization at a wavelength of $365 \mathrm{~nm}$. Swelling experiments were conducted to study the crosslinking density, $\mathrm{pH}$-responsive behavior, and degradation of the hydrogel. Results showed that the degree of swelling of this type of hydrogels increased as the crosslinker concentration (or density) was reduced. Because of the presence of acidic side chains on poly(glutamic acid), swelling behavior was found to be $\mathrm{pH}$ responsive, increasing at high $\mathrm{pH}$ in response to the increase in the amount of ionized acidic side chains. The degradation rate of these hydrogels also varied with $\mathrm{pH}$. More rapid degradation was observed under stronger alkaline condi-
\end{abstract}

tions because of the hydrolysis of the ester bonds between the crosslinker and the polymer backbone. Practically useful degradation rates could be achieved for such hydrogels under physiological conditions. Drug release rates from these hydrogels were found to be proportional to the protein molecular weight and the crosslinker density; increasing at lower protein molecular weight or crosslinker density. The preliminary findings presented in this article suggest that this class of biodegradable hydrogels could be an attractive avenue for drug delivery applications. The specific photoinduced crosslinking chemistry used would permit hydrogels to be synthesized in existence of the entrapped macromolecular drugs including peptides, proteins, and cells. In addition, the rapid feature of this polymerization procedure along with the ability to perform hydrogel synthesis and drug loading in an aqueous environment would offer great advantages in retaining drug activity during hydrogel synthesis. (C) 2002 Wiley Periodicals, Inc. J Biomed Mater Res 62: 14-21, 2002

Key words: hydrogel; photoinduced polymerization; polypeptide; glutamic acid; poly(ethylene glycol); protein release; insulin; lysozyme; albumin

\section{INTRODUCTION}

Hydrogels have been used widely as biomaterials because the high water content renders them biocompatible to the body tissues. ${ }^{1-3}$ As a result, hydrogels have also been investigated intensively over the last

*Present address: Industrial Science and Technology Network, Inc., CYBER Center, 2101 Pennsylvania Avenue, York, Pennsylvania 17404

†Present address: Supelco, Inc., Supelco Park, Bellefonte, Pennsylvania 16823-0048

‡Present address: Southern Research Institute, P.O. Box 55305, Birmingham, Alabama 35255-5305

Correspondence to: V.C. Yang; e-mail: vcyang@umich.edu

Contract grant sponsor: National Institute of Health, Heart, Lung and Blood; contract grant number: HL55461.

(C) 2002 Wiley Periodicals, Inc. decade for use in controlled drug release systems and a variety of other biomedical purposes such as medical implants, diagnostics, biosensors, bioreactors, and bioseperators. ${ }^{1-4}$

Hydrogels are of particular interest in drug delivery applications because their internal architecture can be manipulated to dimensions that accommodate the molecular sizes of the peptide and protein drugs. In addition, the content, density, and length of the crosslinking groups can be used to regulate the pore or mesh size of the swollen hydrogel through which the entrapped drug traverses and is released. ${ }^{5}$ As a consequence, hydrogels can be prepared to possess tailored internal structures that provide specific release rates for different drugs. Alternatively, the hydrogel matrix can also be manipulated to specifically retain drugs within the crosslinked network. In this 
case, drug release can be restricted until degradation of the hydrogel matrix takes place. Because of this flexibility, hydrogels have been investigated as delivery systems for a variety of macromolecular drugs such as peptides, proteins, and genetic-based therapeutics. ${ }^{5}$

Many of the hydrogel systems described in the literature, including the polyacrylate-based systems, however, are not biodegradable, rendering them less suitable as drug delivery platforms. ${ }^{6}$ To overcome this shortcoming, a variety of novel chemistries including the incorporation of biodegradable bonds into the crosslinked hydrogel network have been investigated. ${ }^{7,8}$ For instance, Sawhney et al. ${ }^{8,9}$ reported the preparation of a bioerodible hydrogel by polymerization of the poly(ethylene glycol)-co-poly( $\alpha$-hydroxy acid) acrylate macromer. Heller and coworkers ${ }^{10}$ reported the synthesis of crosslinked hydrogel beads by using unsaturated polyesters. In this case, the release of bovine serum albumin was facilitated by hydrolysis and erosion of the polymer network. Recently, synthetic biodegradable polymers based on monomers that are present in human body, such as poly $(\alpha$-amino acid)s and poly( $\alpha$-hydroxy acid)s ${ }_{1}^{11,12}$ have received considerable interest, simply because both the hydrogel itself and its degradation products possess the least likelihood of eliciting immunogenic responses.

Previously, our group reported on the development of a biocompatible, biodegradable, and $\mathrm{pH}$-responsive polypeptide hydrogel based on poly(L-glutamic acid) (PLG) and poly(ethylene glycol) (PEG). ${ }^{13}$ However, because drug entrapment was carried out by a swelling/diffusion process, the amount of high-molecularweight drug that could be loaded in the gel was relatively low. ${ }^{13}$ To resolve this problem, a novel, photoinitiated crosslinking methodology was introduced during hydrogel synthesis. In this article, synthesis of this new class of PLG-PEG hydrogels is described. In addition, characterization of the swelling and hydrolytic degradation properties of these hydrogels as well as preliminary drug release studies from this hydrogel system were presented.

\section{MATERIALS AND METHODS}

\section{Materials}

PEG with molecular weights of 1000, 2000, and 3400 Da (PEG-1000, PEG-2000, PEG-3400, respectively), poly(ethylene glycol) dimethacrylate (PEG-DMA; molecular weight: $536 \mathrm{Da}$ ), poly(ethylene glycol) methacrylate (PEG-MA; molecular weight: $360 \mathrm{Da})$, methacrylic acid (99\%), anhydrous hydrogen bromide ( $\mathrm{HBr})$, tetrahydrofuran (THF), and dioxane were purchased from Aldrich Chemical Company (Milwaukee, WI). Tetrahydrofuran (THF) and dioxane were refluxed over sodium immediately before use. Insulin (bovine pancreas grade), albumin (bovine, Fraction V, minimum pu- rity: 98\%), lysozyme (chicken egg white), $\gamma$-benzyl-Lglutamic acid (BLG), and triphosgene were purchased from Sigma Chemical Co. (St. Louis, MO).

\section{Methods}

The ${ }^{1} \mathrm{H}$ and ${ }^{13} \mathrm{C}$ NMR spectra were obtained by using a Bruker AMX-300 and AMX-500 NMR spectrometer in deuterated chloroform, DMSO- $d_{6}$, and trifluoroacetic acid, respectively. FT-IR studies were performed on a Nicolet 5-DX infrared spectrometer by using samples prepared in potassium bromide.

Viscosity measurements of poly( $\gamma$-benzyl-L-glutamate) (PBLG) were performed in dichloroacetic acid using a Cannon-Ubbelohde capillary viscometer (Size 75 ) at $25^{\circ} \mathrm{C}$. Molecular weight was then estimated from intrinsic viscosity according to the method of Doty using the following equation $^{11}$ :

$$
[\eta]=2.78 \times 10^{-5} \mathrm{M}^{0.87}
$$

Typically, the PBLG polymers used in our studies had molecular weights of approximately 70-80 kDa.

The benzyl group of PBLG was removed by using either $\mathrm{HBr}$ in benzene or $2 \mathrm{~N} \mathrm{NaOH}$ aqueous THF solution. The molecular weight of the product, PLG, was estimated by from viscosity measurements in $0.2 \mathrm{M} \mathrm{NaCl}$ solution at $\mathrm{pH}$ 7.3 using the intrinsic viscosity-molecular weight relationship derived from Idelson and Blout ${ }^{14}$ :

$$
[\eta]=9.04 \times 10^{-6} \mathrm{M}^{1.01}
$$

\section{Synthesis}

$\gamma$-Benzyl-L-glutamate

$N$-carboxyanhydride (BLG-NCA)

Twelve grams ( $50.6 \mathrm{mmol})$ of BLG was suspended in 150 $\mathrm{mL}$ of anhydrous THF. A solution containing $5.36 \mathrm{~g}$ (18 mmol) triphosgene in $50 \mathrm{~mL}$ anhydrous THF was slowly added over a period of $30 \mathrm{~min}$. The mixture was stirred at $50-60^{\circ} \mathrm{C}$ under nitrogen for about two h until a clear solution was observed. The solvent was removed under vacuum and the product was purified by recrystallization using a mixed solvent of THF and hexane. The yield was $11.21 \mathrm{~g}(84.3 \%)$. The product, BLG-NCA, had a melting point of $89.5-90.5^{\circ} \mathrm{C}$ and a ${ }^{1} \mathrm{H} \mathrm{NMR}\left(300 \mathrm{MHz}, \mathrm{CDCl}_{3}\right)$ spectrum of: $\delta 7.42-7.29$ $(5 \mathrm{H}, \mathrm{m}, \mathrm{Ar}-\mathrm{H}), 6.67(1 \mathrm{H}, \mathrm{s}, \mathrm{NH}), 5.16\left(2 \mathrm{H}, \mathrm{s}, \mathrm{CH}_{2}\right), 4.41(1 \mathrm{H}$, $\mathrm{t}, \mathrm{CH}), 2.62\left(2 \mathrm{H}, \mathrm{t}, \mathrm{CH}_{2}\right), 2.29$ and $2.15\left(2 \mathrm{H}, \mathrm{m}, \mathrm{CH}_{2}\right) \mathrm{ppm}$.

Poly $(\gamma$-benzyl-L-glutamate) (PBLG)

Two grams of BLG-NCA $(7.6 \mathrm{mmol})$ were dissolved in 25 $\mathrm{mL}$ of anhydrous dioxane. After cooling this solution to $4^{\circ} \mathrm{C}$, $30.8 \mathrm{mg}(0.354 \mathrm{mmol})$ triethylamine was added with vigorous stirring. The mixture was stirred at room temperature for $3 \mathrm{~h}$, at which time the polymer was isolated by precipitation in diethyl ether. The polymer was washed with a mixture of dry acetone and diethyl ether and then separately with diethyl ether. The final product, PBLG, was dried un- 
der vacuum at room temperature. The yield was $1.0 \mathrm{~g}$ (59.9\%). ${ }^{1} \mathrm{H}$ NMR $\left(500 \mathrm{MHz}, \mathrm{CDCl}_{3}\right.$ ) spectrum of the final product shows: $\delta 8.30(1 \mathrm{H}, \mathrm{NH}), 7.27\left(5 \mathrm{H}, \mathrm{C}_{6} \mathrm{H}_{5}\right), 5.61(2 \mathrm{H}$, $\left.\mathrm{CH}_{2}\right), 3.97(1 \mathrm{H}, \mathrm{CH}), 2.60$ and $2.28\left(2 \mathrm{H}, \mathrm{CH}_{2}\right), 1.72\left(1 \mathrm{H}, \mathrm{CH}_{2}\right)$ ppm. And its ${ }^{13} \mathrm{C}$ NMR $\left(75.47 \mathrm{MHz}, \mathrm{CDCl}_{3}\right): \delta 25.75\left(\mathrm{CH}_{2}\right)$, $31.05\left(\mathrm{CH}_{2}\right), 57.09\left(\mathrm{CH}_{2}\right), 66.37(\mathrm{CH}), 128.34,128.68,136.21$ (Ar-C), 172.27, $175.63(\mathrm{C}=\mathrm{O}) \mathrm{ppm}$.

PLG: Method (I)

Two and one-half grams of PBLG were dissolved in 250 $\mathrm{mL}$ of benzene. Hydrogen bromide was bubbled through the solution at room temperature for about $90 \mathrm{~min}$ until the solution turned to a gelatinous state. The mixture was allowed to stand overnight. The solid was obtained by filtration and then washed thoroughly with methanol and diethyl ether. The final debenzylated product, PLG, was dried under vacuum. The yield was $1.32 \mathrm{~g}(89.8 \%) .{ }^{1} \mathrm{H}$ NMR $(300$ $\left.\mathrm{MHz}, \mathrm{DMSO}-d_{6}\right)$ spectrum of the product shows: $\delta 12.13$ $(1 \mathrm{H}, \mathrm{COOH}), 8.10(1 \mathrm{H}, \mathrm{NH}), 3.87(1 \mathrm{H}, \mathrm{CH}), 2.24\left(2 \mathrm{H}, \mathrm{CH}_{2}\right)$, 1.87 and $1.78\left(2 \mathrm{H}, \mathrm{CH}_{2}\right) \mathrm{ppm}$. And its ${ }^{13} \mathrm{C} \mathrm{NMR}(75.47 \mathrm{MHz}$, DMSO- $\left.d_{6}\right): \delta 173.67(\mathrm{COOH}), 65.01(\mathrm{CH}), 30.25\left(\mathrm{CH}_{2}\right), 15.25$ $\left(\mathrm{CH}_{2}\right) \mathrm{ppm}$.

PLG: Method (II)

An alternative method was also attempted for debenzylation of PBLG. A $2 N$ sodium hydroxide solution was added dropwise to a solution containing 1.0 $\mathrm{g}$ PBLG in $20 \mathrm{~mL}$ THF, while maintaining the solution at room temperature. The mixture was then heated to $40^{\circ} \mathrm{C}$ for $2 \mathrm{~h}$, followed by the removal of THF under vacuum. The mixture was cooled to $4^{\circ} \mathrm{C}$ and then neutralized with $0.1 \mathrm{~N} \mathrm{HCl}$ to a $\mathrm{pH}$ of 3.0. The white precipitate was collected by filtration. The product, PLG, was washed repeatedly with water until the $\mathrm{pH}$ in the rinsing solutions became neutral.

\section{PEG-MA-graft-PLG}

Before the hydrogel synthesis, PLG was modified by grafting PEG-MA to the acidic side-groups of PLG by using a variety of predetermined molar ratios of the acidic PLG groups to PEG-MA. For example, PEG-MA-graft-PLG with an acid:PEG-MA ratio of 5:1 was prepared by combining $0.10 \mathrm{~g}$ PLG (0.78 mmol glutamate monomer) and $32.2 \mathrm{mg}$ (0.156 mmol) dicyclohexylcarbodiimide (DCC) in $10 \mathrm{~mL}$ $\mathrm{N}, \mathrm{N}$-dimethylformamide along with a three- to fivefold molar excess (relative to the moles of DCC) of PEG-MA and 5 $\mathrm{mg}$ (0.04 mmol) 4-dimethylaminopyridine (DMAP). After stirring for $2 \mathrm{~h}$ at room temperature, the byproduct of this reaction, 1,3-dicyclohexylurea, was removed by filtration. The reaction mixture was then poured into $50 \mathrm{~mL}$ diethyl ether in order to precipitate the final product, PEG-MAgraft-PLG. After filtration, the product was washed with methanol and diethyl ether to further remove any unreacted PEG-MA. The PEG-MA-graft-PLG was then ready to use for hydrogel synthesis without further drying. A small sample of the product, however, was dried under vacuum for NMR characterization. ${ }^{1} \mathrm{H}$ NMR $\left(300 \mathrm{MHz}, \mathrm{F}_{3} \mathrm{CCOOH}\right)$ spectrum shows: $\delta 6.25$ and $5.73\left(=\mathrm{CH}_{2}\right), 4.72--; 3.80\left(-\mathrm{CH}_{2} \mathrm{CH}_{2}-\right), 2.42$ $\left(\mathrm{CH}_{2}\right), 2.34$ and $2.12\left(\mathrm{CH}_{2}\right)$, and $1.94\left(\mathrm{CH}_{3}\right)$ ppm.

PEG-DMA synthesis

PEG of the desired molecular weight (1000, 2000, or 3400 Da) was modified to the dimethacrylate derivative immediately before hydrogel synthesis. In brief, approximately 1.5 mmol PEG was dissolved with excess methacrylic acid (3.6 $\mathrm{mmol}$ ) in about $30 \mathrm{~mL}$ of anhydrous methylene dichloride. Excess coupling agent DCC (3.9 mmol) was added to this solution along with $0.84 \mathrm{mmol}$ DMAP. The solution was stirred at room temperature for about $2 \mathrm{~h}$ at which time the 1,3-dicyclohexylurea byproduct was removed by filtration. The resulting solution was evaporated to dryness under vacuum. To facilitate removal of unreacted PEG and methacrylic acid, the product was purified twice by recrystallization. First, the dried residue was dissolved in acetone, filtered, and then precipitated into diethyl ether. The solid collected from this procedure was then dissolved in methylene chloride and the final PEG-DMA product was obtained following precipitation using ethyl ether. The product was collected, dried under vacuum, and stored in a dark container under vacuum. ${ }^{1} \mathrm{H} \mathrm{NMR}\left(300 \mathrm{MHz}, \mathrm{CDCl}_{3}\right)$ spectrum shows: $\delta 6.13$ and $5.58\left(=\mathrm{CH}_{2}\right), 4.29\left(-\mathrm{CH}_{2}-\mathrm{O}_{2} \mathrm{C}-\right), 3.75$ $\left(\mathrm{OCH}_{2} \mathrm{C}-\mathrm{O}_{2} \mathrm{C}-\right)$, 3.67-3.64 $\left[\left(\mathrm{OCH}_{2} \mathrm{CH}_{2}\right)_{n}\right]$, and $1.95\left(\mathrm{CH}_{3}\right)$ ppm. One PEG-DMA (with a PEG molecular weight of about $536 \mathrm{Da}$ ) was purchased commercially from Aldrich, who could not provide any information regarding the purity of this material.

Hydrogel synthesis by

UV-induced photopolymerization

Hydrogels with different crosslinking density were synthesized by crosslinking PEG-MA-graft-PLG with PEGDMA using equal moles of the methacrylate groups from PEG-MA-graft-PLG and from PEG-DMA. In brief, the experimental procedures were performed by adding $25 \mathrm{mg}$ PEG-MA-graft-PLG and an appropriate molar equivalent of PEG-DMA to $2 \mathrm{~mL} 0.01 \mathrm{M}$ phosphate buffer ( $\mathrm{pH} 7.4$ ) containing $0.9 \mathrm{wt} \%$ sodium chloride. To this reaction mixture, $5 \mu \mathrm{L}$ of a solution containing $300 \mathrm{mg}$ of 2,2-dimethoxy-2phenylacetophenone (i.e., the reaction initiator) in $1 \mathrm{~mL}$ of $N$-vinyl-pyrrolidinone were added. Drug-loaded hydrogels were prepared by adding the drug to this solution before the crosslinking step. In these studies, about $5 \mu \mathrm{g}$ protein was added per milligram of the hydrogel polymer constituents. The polymer solution (either with or without drug) was then placed into a cylindrical microsample tube (i.d. $\sim 6.5 \mathrm{~mm}$ ) and crosslinked by exposure to irradiation $\left(11.6 \mathrm{~mW} / \mathrm{cm}^{2}\right)$ at $365 \mathrm{~nm}$ using a B-100SP Model LWUV lamp (Fisher Scientific). Gelation normally occurred after about $5 \mathrm{~min}$ of irradiation. The hydrogels were rinsed with distilled water several times, and then excess water from the surface of the 
samples was removed. The samples were cut into individual cylinders $\sim 10 \mathrm{~mm}$ in length.

\section{Swelling and hydrolysis studies}

Swelling experiments were performed at several $\mathrm{pH}$ conditions using different buffer solutions including the following: (a) $0.01 \mathrm{M}$ citrate-buffered saline, $\mathrm{pH} 3.0$, (b) $0.01 \mathrm{M}$ phosphate-buffered saline (PBS), pH 7.4, and (c) $0.01 \mathrm{M}$ boric acidbuffered saline, $\mathrm{pH}$ 9.0. Swelling studies were carried out in triplicate by placing dried hydrogel samples into a $20-\mathrm{mL}$ screw-capped glass vials containing $20 \mathrm{~mL}$ of appropriate buffer solutions. The samples were maintained at $37.0^{\circ} \mathrm{C}$ in a Precision Scientific Model 25 reciprocal-shaking bath (Chicago, IL) and shaken at 60 cycles $/ \mathrm{min}$. At specific time intervals, the hydrogel samples were removed from the solution, gently dried to remove excess liquid from the surface and then weighed. The swelling ratio (SR) was estimated as the ratio of the wet hydrogel $\left(m_{\text {wet }}\right)$ to the dry mass $\left(m_{\mathrm{dry}}\right)$ :

$$
\mathrm{SR}=m_{\mathrm{wet}} / m_{\mathrm{dry}} \text {. }
$$

\section{Drug release studies}

Drug release studies were performed in triplicate by placing dried, drug-loaded hydrogel samples into 20-mL screwcapped glass vials containing $20 \mathrm{~mL} 0.01 \mathrm{M}$ PBS. The samples were shaken continuously at $37^{\circ} \mathrm{C}$. At selected time intervals, the hydrogel samples were removed, gently dried, weighed, and placed into new vials containing fresh buffer solutions. The amount of the protein drug released at each time interval was determined by using the Coomassie Plus Protein Assay (Pierce, Rockford, IL). Calculations of the fractional amount of drug released over time were made based on the actual amount of drug that was added during the preparation of the drug-loaded hydrogel.

\section{RESULTS AND DISCUSSION}

\section{Synthesis and characterization}

PBLG was synthesized in dry 1,4-dioxane by ringopening polymerization of BLG-NCA. The reaction was initiated by triethylamine using a monomer-toinitiator molar ratio of 25:1. Polymerization was carried out at room temperature for $3 \mathrm{~h}$ according to the method of Blout et al. ${ }^{12}$ The propagation reaction consisted of a step-wise addition of BLG-NCA to the terminal amino groups of the polymer chain. The degree of polymerization was found to depend on several factors including the monomer (BLG-NCA) concentration, initiator (triethylamine) concentration, reaction time, and reaction temperature. For instance, a higher molecular weight polymer could be obtained by using a lower monomer concentration, longer reaction time, and lower reaction temperature.

The molecular weights of the polymers used in this study are listed in Table I. These results demonstrate that $\mathrm{NaOH}$ debenzylation produced a greater loss in polymer molecular weight than the $\mathrm{HBr}$ method. This was probably caused by a rapid hydrolysis of the peptide bond by the strong nucleophilicity of the hydroxide ion.

As is outlined in Figure 1, PLG was modified to permit photoinitiated crosslinking by attaching PEGMA groups to the free carboxyl side-chain groups of PLG using the activating agent DCC. The ${ }^{1} \mathrm{H}$ NMR spectra in Figure 2 demonstrates the structures of the PBLG, PLG, and PEG-MA-graft-PLG products. As shown, the peaks of the benzyl group at 7.17-7.18 ppm (phenyl) and 4.99-5.07 ppm $\left(-\mathrm{CH}_{2}-\right)$ disappeared after debenzylation of PBLG. On the other hand, the addition of PEG-MA to PLG introduced new signals at 5.73 and $6.25 \mathrm{ppm}\left(=\mathrm{CH}_{2}\right), 3.80 \mathrm{ppm}\left(-\mathrm{CH}_{2}-\mathrm{CH}_{2}-\right)$, and $1.94 \mathrm{ppm}\left(\mathrm{CH}_{3}\right)$, indicating a successful grafting of this side-chain to the PLG polypeptide.

The synthesis of the crosslinker, PEG-DMA, was performed using an excess molar ratio of the methacrylic acid groups as well as the activator agent DCC in order to facilitate conversion of the PEG to the disubstituted product. Two reprecipitations were performed on the product, one using acetone and a second with methylene chloride, in order to remove unreacted PEG and methacrylic acid. In this manner, efforts were made to minimize the presence of unreacted or monosubstituted PEG. The PEG-DMA crosslinker contains alkene bonds at both ends of the PEG chain. Upon exposure to low wavelength UV irradiation, these groups were capable of reacting with the alkene groups on the PEG-MA-graft-PLG, resulting in crosslinking of the PLG backbone to form a three-dimensional PLG-PEG hydrogel network. The FTIR spectra of PLG and the PLG-PEG hydrogel are shown in Figure 3. The spectrum of the hydrogel, in comparison to that of the PLG, showed a new and strong absorption band at about $1103 \mathrm{~cm}^{-1}$, representing the $\mathrm{C}-\mathrm{O}-\mathrm{C}$ stretching vibration of the attached PEG chains. There was also an increase in the intensity of bands at around 2876 and $2931 \mathrm{~cm}^{-1}$ (C-H stretching), which apparently were attributed to the introduction of the PEG crosslinker into the hydrogel. Photopolymerization proceeded very rapidly even though no appreciable efforts were taken to minimize the presence of oxygen before the reaction. As known,

TABLE I

Molecular Weight of PBLG and PLG Polymers

\begin{tabular}{|c|c|c|}
\hline PBLG & $\begin{array}{c}\text { PLG } \\
\text { (HBr Debenzylation) }\end{array}$ & $\begin{array}{c}\text { PLG } \\
\text { (NaOH Debenzylation) }\end{array}$ \\
\hline $78 \mathrm{kDa}$ & $25 \mathrm{kDa}$ & $11 \mathrm{kDa}$ \\
\hline
\end{tabular}




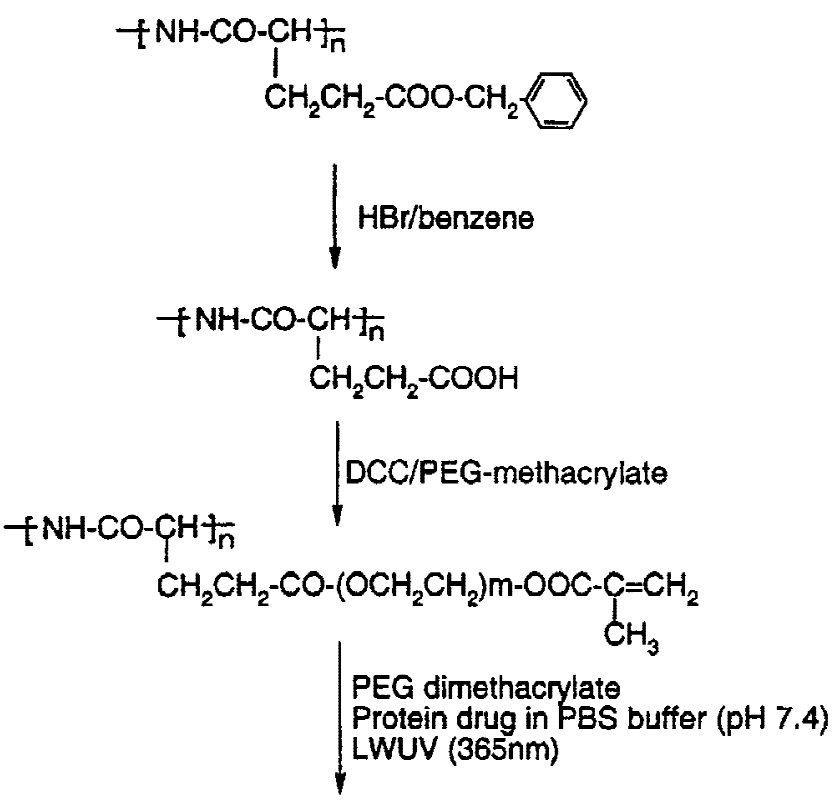

\section{Drug-loaded Hydrogel}

Figure 1. Scheme used to prepare the PLG-PEG hydrogel from the polypeptide, poly( $\gamma$-benzyl-L-glutamic acid), PBLG.

oxygen is usually an inhibitor to the free radicalmediated polymerization. Typically, crosslinking took place within 5 min of exposure to the radiation.

\section{Swelling and hydrolysis behavior of the hydrogels}

The swelling kinetics of hydrogels prepared using different length of PEG crosslinkers was investigated
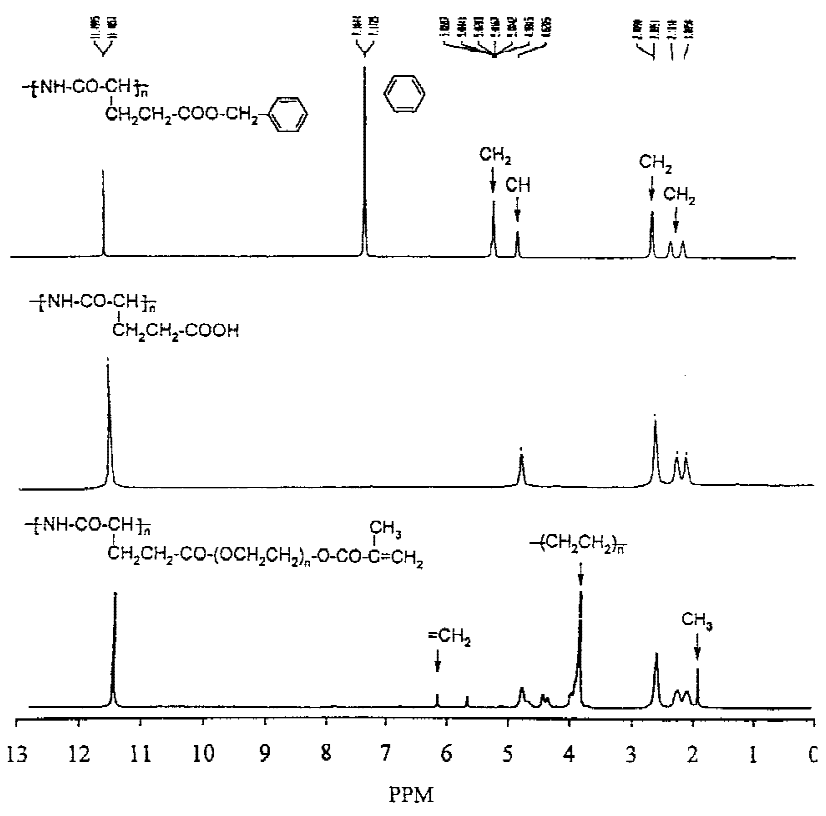

Figure 2. Proton NMR spectra of PBLG, PLG, and PEGMA-graft-PLG.

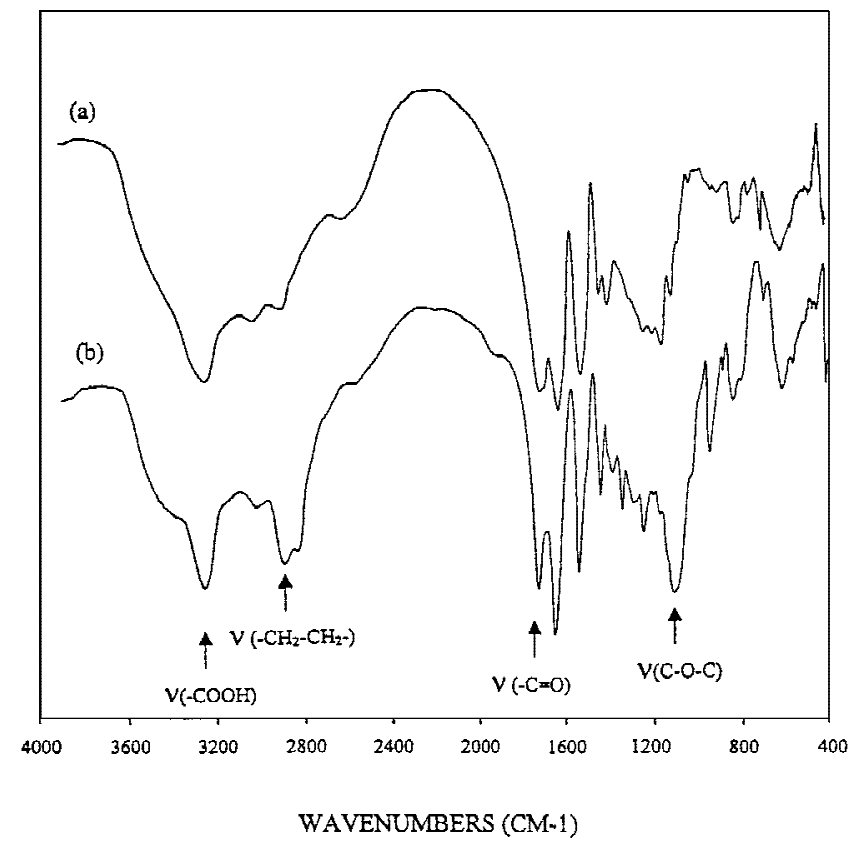

Figure 3. FT-IR spectra of (a) PLG, (b) the PLG-PEG hydrogel.

at $\mathrm{pH}$ 3.0, 7.4, and 9.0. As shown in Figure 4, all hydrogels exhibited a rapid initial hydration within the first several hours of exposure to the aqueous environment. This rapid hydration reflected the highly hydrophilic nature of the polymer constituents of this hydrogel system. At pH 7.4, the gels imbibed $>200 \%$ water within the first hour of swelling.

The profiles seen in Figure 4 clearly demonstrate that swelling increased significantly at higher $\mathrm{pH}$ levels. This was attributed to the stronger electrostatic repulsive force that was produced as the acidic PLG side chains become increasingly ionized. ${ }^{13}$ Equilibrium swelling ratios at $\mathrm{pH} 7.4$ were typically one-half to two-fold higher than the values observed at $\mathrm{pH}$ 3.0. Among the three hydrogel systems studied [Fig. 4(A$\mathrm{C})$ ], the greatest increase in equilibrium swelling occurred at $\mathrm{pH} 9.0$ with the hydrogel containing the 1000-Da PEG crosslinker. At this $\mathrm{pH}$, the overall extent of swelling was observed to decrease with increasing PEG crosslinker molecular weight. As PEG molecular weight increases, the relative number of acid groups within a given weight of hydrogel will decrease. The observations suggest that, in this instance, swelling was primarily influenced by the number density of ionized acid groups within the hydrogel rather than the amount of hydrophilic ethylene oxide groups in the PEG crosslinker.

Swelling experiments conducted over a longer period of time provided evidence for the mechanism by which this hydrogel system degraded. Figure 5 indicated that hydrolytic degradation was base catalyzed, as reflected by the significant increase in rate and extent of swelling that was observed at $\mathrm{pH}$ 9.0. After 

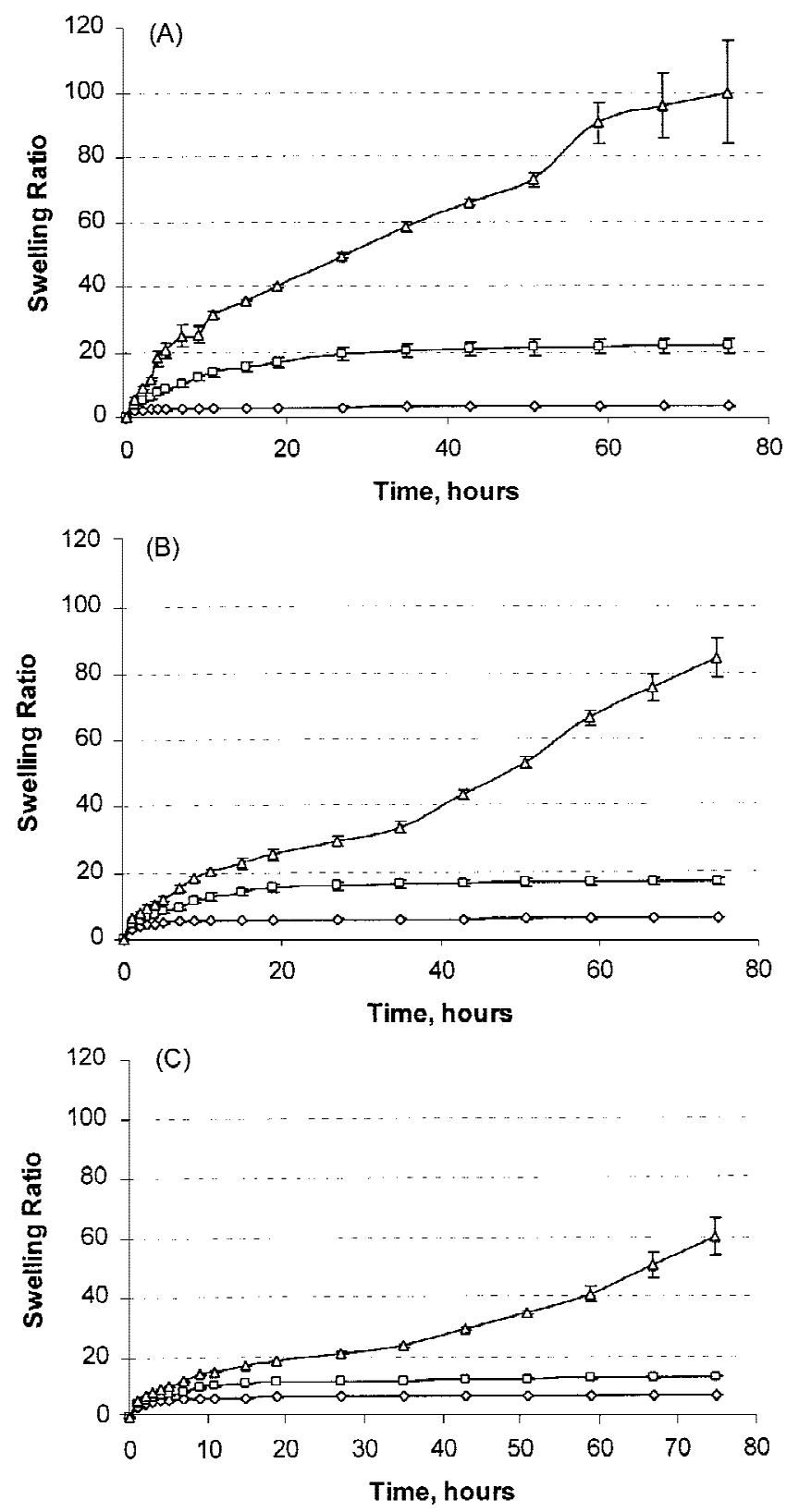

Figure 4. Effects of the molecular weight of the crosslinker on hydrogel swelling behavior at $\mathrm{pH} 3.0(\diamond) ; 7.4(\square)$; and $9.0(\triangle)$. Hydrogels were synthesized at a 10:1 crosslinker ratio using (A) PEG-1000, (B) PEG-2000, and (C) PEG-3400. Each experiment was conducted in triplicate, and error bars represent the standard deviation.

only 3 days at $\mathrm{pH}$ 9.0, hydrogel samples were already degraded to viscous, solution (sol)-like gel. In contrast, the gels swollen at $\mathrm{pH} 7.4$ appeared to be relatively stable for approximately 15 days. By day 23, however, these samples were also degraded to a similar viscous solution state as that attained after 3 days of exposure to $\mathrm{pH}$ 9.0. On the other hand, gel samples maintained at $\mathrm{pH} 3$ were stable and retained their intact structure throughout a 2-month period of study. The basecatalyzed hydrolysis observed could be due to degra-

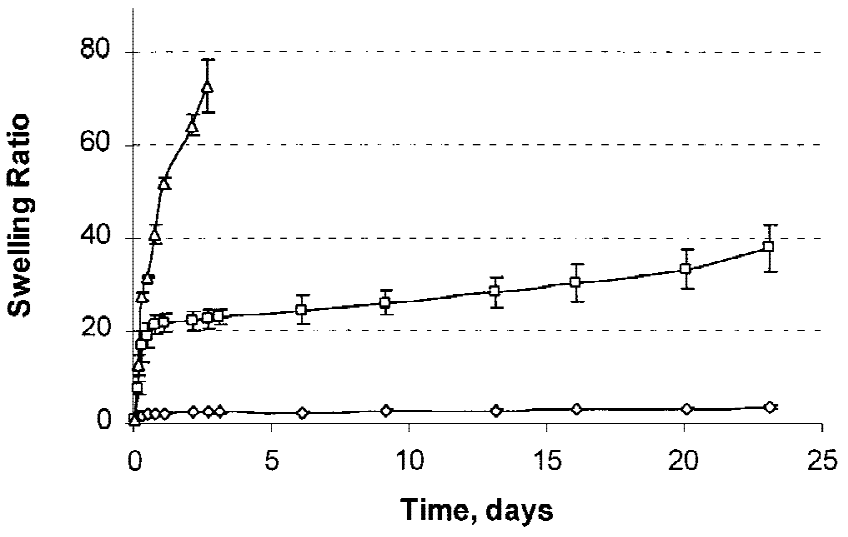

Figure 5. Swelling behavior over time of PLG-PEG hydrogel prepared using the PEG-1000 crosslinker and at a crosslinker ratio of 10:1 at pH $3.0(\diamond), 7.4(\square)$, and $9.0(\triangle)$. Error bars represent the standard deviation of triplicate samples.

dation of the hydrolysis-susceptible amide bonds of the polypeptide backbone and/or the ester bonds formed between PLG and PEG. However, the relatively rapid degradation under moderate $\mathrm{pH}$ (7.4) suggests that hydrolysis of the ester bonds between PLG and PEG may be the primary contributing factor to the observed degradation.

Varying the density of the PEG-DMA crosslinker appeared to be an effective method to manipulate the molecular structure of the crosslinked hydrogel network. Figure 6 depicts the swelling profiles of hydrogels prepared using acid/crosslinker ratios of 10:1, 5:1, and 5:2. As seen, the hydrogel samples under study displayed a greater swelling as the density of the crosslinker decreased. An acid/crosslinker ratio of 5:2 resulted in a hydrogel with an equilibrium swelling ratio of about 6 at $\mathrm{pH} 7.4$, comparing to the value of 8 for the hydrogel prepared at a acid/crosslinker ratio of 5:1. Moreover, a dramatically increase in the swelling ratio was observed at the lowest crosslinker ratio of 10:1. Obviously, a lower density of the crosslinker

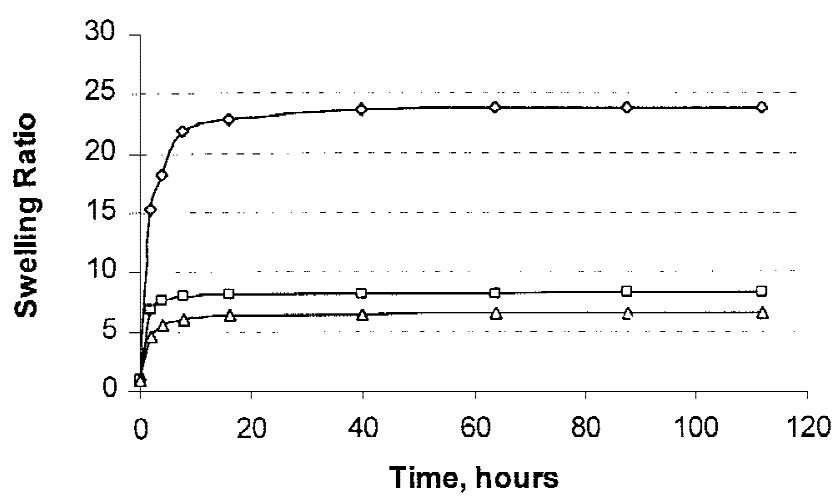

Figure 6. Swelling characteristics at pH 7.4 of a PLG-PEG hydrogel prepared using a PEG-536 crosslinker and a crosslinker ratio of $10: 1(\diamond) ; 5: 1(\square)$; and 5:2 $(\triangle)$. 
would produce a hydrogel network with a greater distance between polymer chains, rendering the network less resistant to electrostatic and hydrophilic swelling forces.

These findings suggest that either the number density or molecular weight of the crosslinker can be used to manipulate the degree of swelling of the hydrogel. Consequently, these factors also represent possible means to regulate the effective release rate of the drug entrapped within the hydrogel network.

\section{In vitro protein release studies}

The release of several model proteins was investigated using hydrogels prepared with the 536-Da PEGDMA crosslinker at acid/crosslinker ratios of 10:1, 5:1, and 5:2. Figure 7 shows the release profiles of insulin, lysozyme, and albumin; a group of proteins that represent a broad range of molecular weights $(5,800$, 14,300 , and $66,400 \mathrm{Da}$, respectively). A rapid release during the first $16 \mathrm{~h}$, which was relatively independent on the molecular weight of the protein, was observed for all these three proteins. This relatively constant drug release during the initial period was likely attributed to a burst release of the drug that was available at the hydrogel surface before the swollen gel barrier was established. After $16 \mathrm{~h}$ and longer, however, release rates were influenced by the molecular weight of the protein drug as well as the density of the crosslinker in the hydrogel network. For instance, smaller proteins such as insulin displayed relatively rapid release. Indeed, insulin release was nearly complete within about 2.5 days from hydrogels with crosslinker ratios of 10:1 and 5:1. In contrast, a complete release of lysozyme required at least 10 days, whereas during the same span of time, release of albumin was only about $40-60 \%$. On the other hand, all protein release was prolonged using hydrogels containing higher crosslinker ratios. At the highest crosslinker ratio, the duration of insulin release was doubled to about 5 days and a similar trend was observed for both lysozyme and albumin. Overall, increasing the crosslinker density resulted in a reduction in drug release rate from the hydrogel network.

The synthesis of the described hydrogel network by photoinitiated crosslinking in the presence of the drug compounds offers several potential advantages. First, crosslinking of the polymer can be achieved specifically without the possibility that the drug itself may also be covalently linked to the polymer matrix during the crosslinking process. Second, unlike loading the drug by the conventional swelling/absorption mechanism where steric hindrance could result in heterogeneous drug loading and distribution, a consistent drug loading could be obtained for the described hydrogel

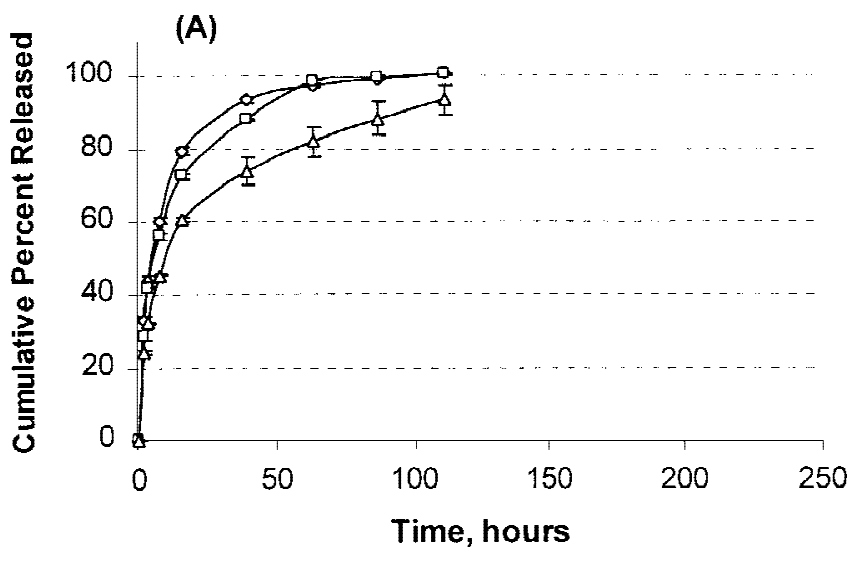

(B)
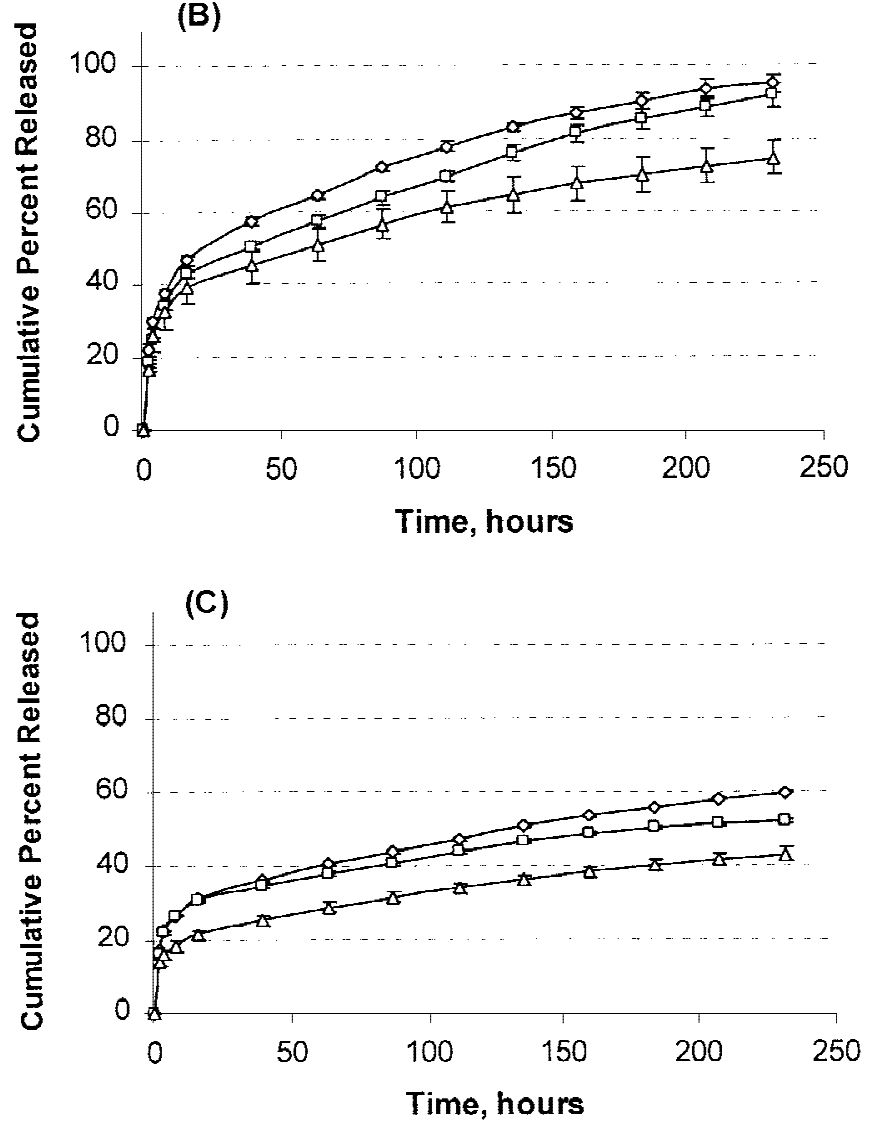

Figure 7. Drug release profiles from PGA-PEG hydrogels prepared using the PEG-536 crosslinker and crosslinker ratios of 10:1 $(\diamond), 5: 1(\square)$, and 5:2 $(\triangle)$. Release experiments were performed in $0.01 \mathrm{M}$ PBS $(\mathrm{pH} 7.4)$ at $37^{\circ} \mathrm{C}$ using (A) insulin, (B) lysozyme, and (C) albumin. Error bars represent the standard deviation of triplicate samples.

system. Last but not least, manipulation of the crosslinker density can be used to achieve a desirable and regulated drug release rate.

\section{CONCLUSIONS}

In summary, a novel polypeptide hydrogel system composed of PLG as the polymer backbone and PEG 
as the crosslinker was synthesized using a photoinitiated crosslinking chemistry. Similar to our earlier PLG-PEG polypeptide hydrogel, ${ }^{13}$ which was synthesized by conventional crosslinking chemistry, this hydrogel also showed a $\mathrm{pH}$-responsive swelling behavior. Changes in the crosslinker density and the chain length influenced the swelling characteristics of these hydrogel systems. Unlike the polypeptide hydrogel system previously developed, ${ }^{13}$ this new crosslinked hydrogel system, because of the introduction of ester bonds into the crosslinking scheme, was degradable by hydrolysis over a time span and $\mathrm{pH}$ conditions that were practically required. Because this hydrogel could be synthesized directly in the presence of the drug compound, high drug loading could be readily achieved. In vitro release studies demonstrated that the molecular weight of the entrapped drug would influence its release rates, and modification of hydrogel network structure could be used directly to regulate the drug release profile.

\section{References}

1. Gombotz WR, Hoffman AS. Immobilization of biomolecules and cells on and within synthetic polymeric hydrogels. In: Peppas NA, editor. Hydrogels in medicine and pharmacy, Vol. 1. Boca Raton, FL: CRC Press, Inc.; 1986. p 95-126.

2. Peppas NA, Korsmeryer RW. Dynamically swelling hydrogels in controlled release applications. In: Peppas NA, editor. Hydrogels in medicine and pharmacy, Vol. 3. Boca Raton, FL: CRC Press, Inc.; 1987. p 109-135.

3. Hoffman AS. Conventional and environmentally-sensitive hydrogels for medical and industrial uses: a review paper. In:
Deross D, Kajiwara K, Osada Y, Yamauchi A, editors. Polymer gels. New York: Plenum Press; 1991. p 289-297.

4. Colombo P, Catellani PL, Peppas NA, Maggi L, Conte U. Swelling characteristics of hydrophilic matrices for controlled release. New dimensionless number to describe the swelling and release behavior. Int J Pharm 1992;88:99-109.

5. Lowman AM, Peppas NA. Hydrogels. In: Mathiowitz E, editor. The encyclopedia of controlled release. New York: John Wiley and Sons; 1999. p 397-418.

6. Markland P, Yang VC. Biodegradable polymers as drug carriers. In: Swarbrick J, editor. Encyclopedia of pharmaceutical technology, 2nd edition. New York: Marcel Dekker, Inc. 2002. In press.

7. Kamath KR, Park K. Biodegradable hydrogels in drug delivery. Adv Drug Delivery Rev 1993;11:59-84.

8. Sawhney AS, Pathak CP, Hubbell JA. Bioerodible hydrogels based on photopolymerized poly(ethylene glucol)-co-poly $(\alpha-$ hydroxy acid) diacrylate macromers. Macromolecules 1993;26: 581-587.

9. Sawney AS, Pathak CP, Van-Rensburg JJ, Dunn RC, Hubbell JA. Optimization of photopolymerized bioerodible hydrogel properties for adhesion prevention. J Biomed Mater Res 1994; 28:831-838.

10. Heller J, Helwing RF, Baker RW, Tuttle ME. Controlled release of water-soluble macromolecules from bioerodible hydrogels. Biomaterials 1983;4:262-266.

11. Toty P, Bradbury JH, Holtzer AM. Polypeptides. IV. The molecular weight, configuration and association of poly- $\gamma$-benzylL-glutamate in various solvents. J Am Chem Soc 1965;78:947954.

12. Blout ER, Karlson RH. Polypeptide. III. The synthesis of high molecular weight poly- $\gamma$-benzyl-L-glutamates. J Am Chem Soc 1965;78:941-946.

13. Markland P, Zhang Y, Amidon GL, Yang VC. A pH- and ionic strength-responsive polypeptide hydrogel: Synthesis, characterization, and preliminary protein release studies. J Biomed Mater Res 1999;47:595-602.

14. Idelson M, Blout ER. High molecular weight poly- $\alpha, \mathrm{L}-$ glutamic acid: Preparation and optical rotation changes. J Am Chem Soc 1958;80:4631-4634. 